\title{
Climate Responsive Design and Features Explore of Paul Rudolph's Light Wood Residences
}

\author{
Xue Jihui ${ }^{1}$, Zhuang Shaopang ${ }^{1}$, Lan Xinning ${ }^{2}$ \\ ${ }^{1}$ South China University of Technology, School of Architecture, State Key Laboratory of Subtropical Building Science, Tianhe, \\ Guangzhou, Guangdong, China \\ 2 Jiangsu F\&T Co., LTD., Xuanwu, Nanjing, Jiangsu, China
}

\begin{abstract}
In the middle of the 20th century, Paul Rudolph's design practice of light wood residences in Sarasota area was well adapted to the local hot and humid subtropical climate. By tracing the origin of Paul Rudolph's thought of climate responsive design, it's possible to realize the design features of Paul Rudolph's early works from heat protection and ventilation, and sum up the strategies and construction of his light wood residences for climate responsive design. Based on the characteristics of subtropical heat and humidity, Rudolph focused on innovations in building facades, roofs, and spaces, and proposed a series of climate-responsive design strategies and methods. Rudolph's light wood practice has its own value in terms of technical principles, material technology, and regional characteristics, which are both rational and perceptual, and has enlightening value for the application of light buildings in subtropical areas and the design of contemporary light wood buildings.
\end{abstract}

\section{Introduction}

Paul Rudolph has received attention for his contributions in the field of modern architectural design and education $^{[5]}$. His early light wood residences practice in the Sarasota area made useful explorations in subtropical hot and humid climate responsive design. Although practical research on the light building system of contemporary architects are not a minority, there are relatively few studies on the climate responsive design of light buildings. For example, the Final Wooden House of Sou Fujimoto focuses on the integration of architecture and environment ${ }^{[1]}$, Kengo Kuma's Hiroshige Art Museum focuses on handling materials ${ }^{[2]}$, and Zhu Jingxiang's "Sprout System" pays more attention to rapid prefabrication and installation research ${ }^{[3]}$. Therefore, studying the climate adaptation design of Paul Rudolph's light wood residences has practical value.

\section{The formation of new architectural style in Sarasota}

The Sarasota area is located in Florida in the southern United States, bordering the Gulf of Mexico, and have pleasant subtropical climate and beautiful natural beaches. At the beginning of the 20th century attracting more and more northerners to visit and live, the Sarasota area developed rapidly. Mediterranean-style architecture quickly became popular with its unique charm and exoticism. But its thick walls and small openings for doors and windows showed its inherent inadequacy in
Sarasota's hot and humid climate, with poor indoor ventilation, humid and hot, and poor comfort ${ }^{[10]}$.

Architect Ralph Twitchell once in the paper "Where will Sarasota go" called on people to pay attention to the local climate and develop new architectural styles to adapt to the hot and humid climate versus people yearn for open and free lifestyle ${ }^{[10]}$. After World War II, American economy and society developed rapidly, and the demand for small houses in the southern subtropics has increased significantly. Paul Rudolph came to Sarasota in 1941 and worked for Twitchell for half a year before entering Harvard Design Institute in the fall. Rudolph was involved almost all the way in the construction of Twitchell's own house, and this became the beginning of Rudolph's practice in Sarasota. Later since World War II and academic reasons, Rudolph returned to Sarasota in 1947 for architectural practice and gradually became a partner of Twitchell. They parted ways in 1951, and Rudolph set up his own studio in Sarasota. Rudolph's practice in Sarasota came to an end in 1958 when he accepted the appointment of director of Yale School of architecture.

Paul Rudolph and other architects combined with the local climate, environment, economy and technology, from the facade, roof, space and other aspects, and then designed a series of subtropical light wood residences to meet the requirements of shading, heat insulation, ventilation and moisture-proof (Table 1). It was increasingly accepted by the public for its adaptability to the local climate, easy access to materials, open and free form, and integration of the environment.

\footnotetext{
$\overline{{ }^{*} \text { Corresponding author: 53119@qq.com }}$
} 
Table 1. Summary of climate responsive design methods for Rudolph's major projects

\begin{tabular}{|c|c|c|c|}
\hline \multirow{2}{*}{ Projects } & \multicolumn{3}{|c|}{ Climate Responsive Design } \\
\cline { 2 - 4 } & $\begin{array}{c}\text { Facade } \\
\text { Shading }\end{array}$ & $\begin{array}{c}\text { Roof } \\
\text { Shading }\end{array}$ & $\begin{array}{c}\text { Flow } \\
\text { Space }\end{array}$ \\
\hline Healy Cocoon House & $\bullet$ & $\bullet$ & $\bullet$ \\
\hline Walker Guest House & $\bullet$ & & $\bullet$ \\
\hline Hook Guest House & $\bullet$ & $\bullet$ & $\bullet$ \\
\hline Harkavy Residence & $\bullet$ & $\bullet$ & $\bullet$ \\
\hline Hiss Umbrella Residence & $\bullet$ & $\bullet$ & $\bullet$ \\
\hline
\end{tabular}

\section{Paul Rudolph's light wood residential space layout and enclosure system}

\subsection{Open flow space}

Space fluidity is the basic characteristic of modern architectural space, and it is also one of the basic strategies of architectural climate responsive design in contemporary subtropical climate regions ${ }^{[8]}$. The flow space not only gives people a rich and changeable feeling in psychology, but also adjusts the indoor comfort through air convection, ventilation and heat dissipation $^{[8]}$. Paul Rudolph arranges the building around the central courtyard in the Deman Residence (1946), and designs a circular corridor. Part of the building is connected from east to west, and the internal and external spaces are infiltrated each other. The courtyard in the middle has a certain effect of pulling out the wind (Figure 1). In Finney Guest House (1947), Rudolph treats the interior space as linear, which promotes the ventilation in both horizontal and vertical directions ${ }^{[10]}$ (Figure 2). Rudolph called it "An assembly line space reached the top on the dining table of an interior space". In Healy Cocoon House (1950), Rudolph occupies one side of the bedroom and bathroom in a short depth, and the other bedroom is located in the middle of the house with a flexible partition. The flexible partition in the middle can be opened, and the plane is close to the traditional corridor style house in the southern area, which can obtain the best ventilation effect ${ }^{[5]}$ (Figure 3 ).

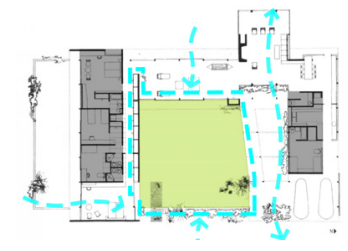

Fig. 1. Deman Residence

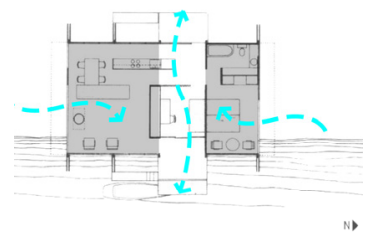

Fig. 3. Healy Cocoon House

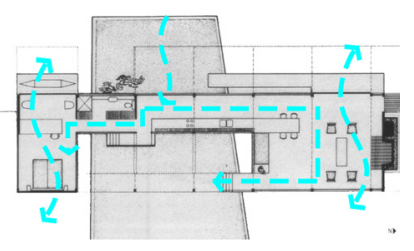

Fig. 2. Finney Guest House

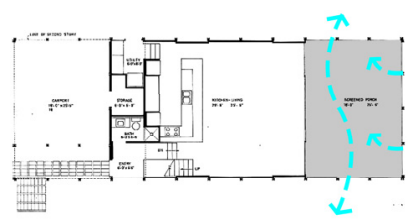

Fig. 4. Harkavy Residence
The screened porch is one of Paul Rudolph's innovative ideas. In the Harkavy Residence (1957), Rudolph combines the screen windows with the surrounding porch in the traditional southern architecture. The porch was built together with the main building, and the appearance was unified. The gauze doors and windows are used to block flying insects and facilitate indoor ventilation, forming a living space suitable for the changeable climate in subtropical areas ${ }^{[5]}$. The screened porch serves as a transitional area that well connects the indoor and outdoor spaces, and brings the external natural scenery into the interior ${ }^{[5]}$ (Figure 4).

\subsection{Flexible facade shading}

Paul Rudolph's facade shading mainly uses adjustable wooden shutters, external wooden grilles, movable hinge board and so on.

As a wall structure, the adjustable wooden shutter can be directly landed, which has a wide field of vision and better integrity. The window sash is of uniform specification and convenient for prefabrication and assembly. This kind of window sash is used in Healy Cocoon House, Leavengood Residence (1950), Hook Guest House (1952) and Biggs Residence (1955). With the blinds, people can adjust the light, shadow and vision of the room at will, with higher controllability and richer indoor space changes. The division of facade is more delicate, which makes the building more dynamic and lively. In addition, in Hook Guest House, some shutters are replaced with transparent glass panels to better enjoy the lake scenery, and in Biggs Residence, some shutters are replaced with fixed wood wallboard to better protect privacy.

Rudolph used external wooden grilles in Martin Harkavy Residence (Figure 5). The grating on the side of the glass window filters part of the light, creating a light and shadow effect that changes with time in the room. The level of indoor space is more abundant, forming three levels: outdoor, transition area and indoor. The facade presents the effect of hazy beauty, which increases the sense of depth.

The movable hinge board can realize active and accurate sunshade, and cooperate with insect screen window to better adapt to the subtropical climate environment. The design concept of this project comes from Rudolph's naval experience. The design concept of modern ships makes Rudolph's architectural practice light and efficient. Rudolph used this kind of sunshade system in Finney Guest House, Walker Guest House (1952) (Figure 6), Cohen Residence (1953) and Grand Rapids Model House (1955). At the same time, architects such as Le Corbusier and Xia Changshi used fixed or adjustable shutters to design the facade climate responses in tropical and subtropical regions. The movable hinge board, which combines the wall structure with the sunshade, has its own regional characteristics. 

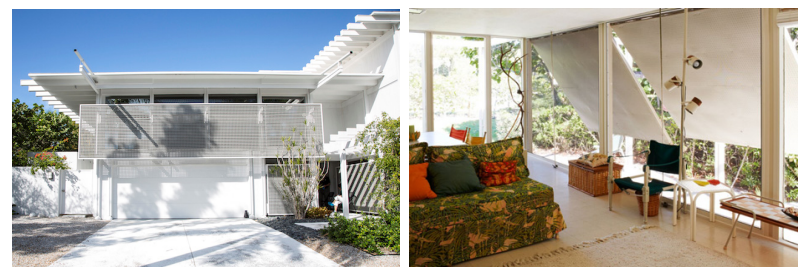

Fig. 5. Harkavy Residence

Fig. 6. Walker Guest House

\subsection{Light roof shading}

Affected by Wright's far-reaching floating eaves, Rudolph often overhangs the roof truss and roof panel together with a deeper eaves, which are light and expressive in shape. Deman Residence, Siegrist Residence (1948), Haskins Residence, Harkavy Residence, etc. all apply this technique (Figure 7).

The double-layer roof is another useful attempt by Rudolph to shading the roof, which enhances the heat dissipation effect. This concept first appeared in Watson Residence (1950), Rudolph added a canvas sunshade under the roof of the dining room to improve the indoor thermal environment ${ }^{[10]}$ (Figure 8). In Haywood Apartments (1952) and Hiss Umbrella Residence (1953), Rudolph used a wooden grid roof to cover the main space of the building. The sun shines through the roof lattice to form rich light and shadow, which is very subtropical feature. Therefore Hiss Umbrella Residence has become one of Rudolph's most typical masterpieces.

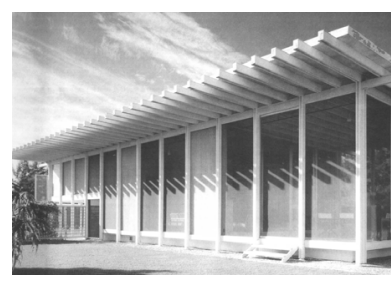

Fig. 7. Harkavy Residence

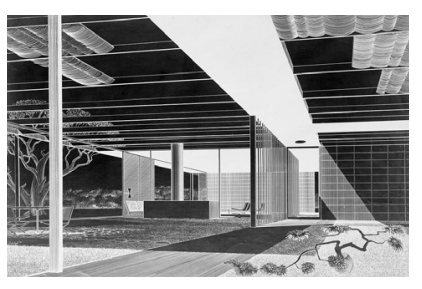

Fig. 8. Watson Residence

\section{Paul Rudolph's modernist origins in the climate responsive design of the light wood residences}

\subsection{Time background}

The middle of the 20th century was an important period in the climate responsive design of modernist buildings in the tropics. Starting from the first concrete shading device designed by Corbusier in the early 1930s, the tropical areas have carried out the practice of shading concrete skin. The development of modern technology and materials made the 1950s and 1960s a new era for the exploration and development of climate responsive design strategies in tropical areas. By the late 1960s, the architectural circles began to focus on energy and ecology, and the practice of concrete shading came to an end with the death of Corbusier ${ }^{[6]}$.

In the early days, such as the Brazilian Ministry of Education and Health Building designed by Corbusier, Costa and Niemeyer in 1936 and the Indian Monk
Residence designed by Anthony Raymond both used concrete blinds ${ }^{[4]}$. Due to the disadvantages of concrete, such as poor air permeability, long construction period, poor seismic resistance, and not easy to prefabricate and assemble, Maxwell Fry \& Jane Drew, who have cooperated with Corbusier, once pointed out that the concrete sunshade became a heat storage body to dissipate heat indoors at night.

In the next 20 years, Corbusier continued to explore the architectural form language to cope with the hot climate, and gradually matured in the continuous exploration. For example, in the 1950s, he believed that in order to cope with the humid and hot climate in India, architectural design should focus on controlling humidity and temperature to meet the indoor comfort ${ }^{[9]}$. The overhead roof slab, facade blind, first floor overhead, cantilever floor panel and other building forms can reduce solar radiation and glare, promote indoor ventilation, and then increase indoor comfort. The tropical buildings in this stage all reflected this kind of form characteristics, which could better cope with the local climate and form their own unique architectural forms. Such as the Chandigarh High Court designed by Le Corbusier in 1951, the Millers Union in 1952, etc.

In 1953, Karl Langer used cantilevered wooden sheds, slanted windows, fish ponds, etc. to respond to the local climate in a Western Furniture Showroom design in Queensland, Australia ${ }^{[7]}$. In the same year, Hayes and Scott used east-west walkways to ventilate the Pfechenmel House in Queensland. It's the first time that they used louvered roofs for shading in Australia ${ }^{[7]}$. In 1962, Polish architects Jacek Chyrosz and Stanislaw Rymaszewski used ingenious roof design in the design of the Accra International Trade Fair in Ghana to solve climate problems, such as rainwater drainage, building ventilation, glare control and natural lighting ${ }^{[4]}$.

\subsection{Master's influence}

Wright's concept of integrating architecture and environment, Gropius's prefabricated building concept, and Mies's modular design concept all had a certain impact on Paul Rudolph when he was a student, and it was directly reflected in light wood residences practice in Sarasota area.

In 1940, Wright designed the Rosenbaum Residence in Alabama. This "L-shaped" house is located near the residence of Rudolph's parents. The use of cypress, brick, glass and other materials, as well as the horizontal extension of the figure, showed Wright's consistent style $^{[10]}$. The overhanging space formed by Wright's iconic cascading far-reaching floating eaves has climatic significance in the mild and humid southern region. Most of the rooms in the residence have doors which lead directly to the outside and integrate the building with the local natural scenery. This building impressed Paul Rudolph, who just graduated from Alabama Institute of Technology.

In 1941, Paul Rudolph entered Harvard University. Gropius and Marcel Breuer have studied prefabricated buildings, such as the Family House designed by 
Gropius in 1937. Its simplified three-dimensional form, strip-shaped windows, walls connected by thin plates, the combination of wood and low pebble walls, transitional porches and other concepts have had a certain impact on Paul Rudolph ${ }^{[10]}$. The course "Mapping of American Historic Buildings" taught by Walter Burkhardt enabled Rudolph to learn a lot of southern architecture's methods of dealing with climate and environmental relations, such as movable shutters, awning systems, and laminated panels, etc. ${ }^{[10]}$ These are reflected in Rudolph's Sarasota design projects.

Mies van der Rohe also had an important influence on Rudolph, such as the modular design and the concept of "homogeneous space" in Farnsworth House which were reflected in Rudolph's Walker Guest House. In a retrospective exhibition of works designed by Mies himself in 1947, Rudolph observed and studied Mies' Resor Residence in Wyoming ${ }^{[10]}$. This residence spanning the creek is a box made of glass and wood. The large area of glass integrated the internal space with the surrounding natural environment to form a free and open space. Rudolph's Finney Guest House design focuses on the expression of linear structure, the visual consistency and integration of the residence and the surrounding landscape, which clearly reflects the existence of this influence ${ }^{[10]}$.

\section{Technical features of Rudolph's light wood residences climate responsive design}

\subsection{Technical features of fabricated structure based on materials}

The climate responsive design explorations of Le Corbusier, Anthony Raymond, Jacek Chyrosz and others were mainly for heavy concrete structures, such as reinforced concrete louvers, concrete breathing walls, etc. While Paul Rudolph and Queensland architects mainly focused on the exploration of light wood architectures, such as wooden shutters, wooden shuttered roofs, etc.

Paul Rudolph and other architects started from the weak links of the facade and roof and used components to directly block the sunlight to prevent the sun from directly entering the room, such as facade shading components, roof floating eaves, etc. This method is the most direct and effective. In contrast, Rudolph's light wood shading components are adjustable, such as adjustable shutters and adjustable hinges, which are more flexible and lighter in form. Secondly, they all adopt the principle of hot-press ventilation for heat dissipation, such as Rudolph's external wooden grille, double-layer roof structure and flow space, Anthony Raymond's arched roof insulation, Polish architects' folded roof, etc. The principle is applied in these architectures. Although these methods are quite different, they all have their own characteristics and show a good shading and ventilation effect.

The main architects of the Sarasota School of Architecture are Ralph Twitchell, Paul Rudolph, Victor
Lundy, etc. Twitchell's characteristic is that he pays attention to the physical properties, craftsmanship and details of building materials. His own designs have a strong appearance, such as the use of lacquered cypress wood and heavy colors ${ }^{[10]}$. Rudolph's characteristic is to focus on the use of lines and spaces rather than materials. The works he completed alone are always in the original wood color, which are more vivid and brisk compared to Twitchell ${ }^{[10]}$. Lundy's buildings are mostly public buildings. Lundy mostly used roof canopies and selfshading to coordinate the climate, and the appearance is often curved and lively ${ }^{[10]}$. Such as the Church for the Presbyterian Congregation of Venice/Nokomis (1954), the Warm Mineral Springs Inn (1959), etc. In contrast, Paul Rudolph's climate responsive design strategy is more delicate and emphasizes practical simplicity. His architectures don't emphasize the expression of style as much as Lundy, and don't stress the expression of materials as much as Twitchell. His architectures start from the architectural space and practicality, take into account the requirements of economy and beauty, adopt modular and prefabricated methods, and present their own characteristics.

Both Paul Rudolph and Twitchell used locally grown cypress as the main building structure, which has the advantages of low cost, environmental protection, corrosion resistance, and lightweight prefabrication. They used the linear features and texture of cypress wood to develop the Ocala lime slab ${ }^{1)}$, which formed the technical characteristics of the Sarasota area ${ }^{[10]}$.

\subsection{The regional cultural value of breaking through the "International Style"}

All are the exploration and transformation of the "International Style" architecture, taking Paul Rudolph's Healy Guest House as an example. Rudolph implements the rational thinking of the "International Style" on the facade, and uses floor-to-ceiling wooden shutters to improve shading performance and privacy. The overall form of the building presents a simple rectangle, which can integrate the surrounding environmental factors (such as sea breeze, sound of waves, sea water smell, etc. $)^{[10]}$. This idea is similar to Wright's "Grassland Architectural Concept". The overall form of the building is light and open, which is lighter than the heavy concrete structure, making it one of the local characteristic buildings in Sarasota. As for Mies van der Rohe's Finsworth House and Philip Johnson's Glass House (1949), their facades use large-area glass windows and steel structures, which are more stylish for simplicity. They are standard "International Style" architectural forms, which are different from Rudolph's architectures. In addition, Rudolph's adjustable hinges, double-layer roof structure, and screened porch combined with modular, prefabricated climate responsive design strategy are his own unique and innovative designs. These strategies have proved to be well adapted to the subtropical climate, making his buildings more distinctive in local style. For example, Rudolph used a unified and detailed modular design 
from the plane to the facade in the Walker Guest House like Mies' Farnsworth House, which not only improved the shading effect, but also improved the integrity of the house and made it more formal and easier to achieve prefab assembly.

\section{Summary and thinking}

Paul Rudolph absorbed the ideas of architects such as Wright, Mies, and Gropius, and carried out the climate responsive design practice of light wood residences in Sarasota according to local conditions. Finally, these practice gradually became the local characteristic architectural style of Sarasota. This style has an important impact on later subtropical and tropical architectures, and also has important value for contemporary climate responsive design concepts. Based on the characteristics of subtropical heat and humidity, Rudolph focused on innovations in building facades, roofs, and spaces. Starting from practical, economical and aesthetic requirements, Rudolph proposed a series of climate-responsive design strategies and methods and applied them in practice. On the other hand, Rudolph's light wood practice has its own value in terms of technical principles, material technology, and regional characteristics, which are both rational and perceptual. Such as convenience, adjustability, low price, energy saving, environmental protection, lightness, etc. These strategies, methods and concepts are not out of date today, which are conducive to promoting the development and promotion of passive energy-saving design in subtropical regions.

In the same period, the Chinese architect Xia Changshi practiced concrete shading components. He tried cast-in-place panels, prefabricated panels and other forms, as well as wooden shutters for sunshades. Mr.Xia and Rudolph's designs have their own characteristics, and both promote the development of climate responsive design in tropical and subtropical regions. Contemporary building technology and material performance are more mature, people have higher requirements for comfort, and climate adaptability design develops from perceptual design to quantitative optimization. The researches on the absorption and application of Rudolph's light wood residences' climate responsive design strategies should be combined with contemporary technology, and carries out in-depth from the aspects of green health, prefabrication, and environmentally friendly design. Such researches will further promote the development of contemporary green building design in tropical and subtropical regions.

\section{Source of Figures and Tables}

Figure 5: https://www.saf-srq.org/architecture/martin-har kavy-house/

Figure 6: https://archive.curbed.com/2019/1/4/18168439/ paul-rudolph-walker-guest-house-for-sale

Figure 7, 8: quoted from Paul Rudolph: The Florida Houses

Others are drawn by the author himself.

\section{Notes}

1) Ocala Lime Board is a method of making lime slabs in Ocala, Florida. This lime slab is made of crushed limestone and has a pleasing light yellow. The frame and the lime board are connected by thin mud. The walls of the house are coated with silicon to prevent water seepage. Several vents are left on the top of the wall and the ground to alleviate the problems of indoor humidity, mold, and mosquitoes. This technique was developed by Wright in the construction of California houses in the 20th century. Regardless of the location, the lime boards have the same appearance, so the external space and the internal space look like two parts of the same whole. Rudolph's choice of this lime board technology also represents his understanding of the local special climate $^{[10]}$.

\section{Acknowledgments}

This article is one of the phased achievements of the general project of the National Social Science Fund Research on Theories and Key Technologies of Green Building Assembly Development in Hot and Humid Climate (2018A030313902 Natural Science Foundation of Guangdong Province).

\section{References}

1. Luo, Q., Ji, X. (2020) Sou Fujimoto - the ambiguous expression of architecture. Huazhong Architecture, 38(10):42-45.

2. Chen, S., (2009) Kengo Kuma and his Matoucho Hiroshige Art Museum. Scientific and Technological Innovation, (06): 230.

3. Chen, LZ., (2019) "Light" cavalry in Rural Construction -- Zhu Jingxiang's light construction system and its practice in rural areas. World Architecture Review, 34 (01): 5-8.

4. Zhuang, SP., (2019) On some clues of the practice of tropical modernism architecture in the 20th century. South Architecture, (03): 96-101.

5. Lan, XN. (2019) A study on the practice of early Tropical Architecture in Paul Rudolph. South China University of Technology.

6. Chen, QR. (2011) Preliminary study on the development course of climate adaptation design of building skin in hot area (1930-1980). South China University of Technology.

7. Macarthur, J., Van der Plaat, D., Gosseye, J., Wilson, A. (2015) Hot Modernism Queensland Architecture 1945-1975. Artifice books on architecture, London.

8. Mai, H. (2015) Analysis on the Climate Adaptability Strategy of Modern Lingnan Architecture. Huazhong Architecture, 33 (06): 29-33.

9. Wu, GD. (2020) Climate Adaptability Design and Enlightenment in the Process of Building Modernization in Hot Areas. Urbanism and Architecture, 17 (04): 71-75. 
10. Domin, C., King, J. (2005) Paul Rudolph: The Florida Houses. Princeton Architectural Press, State of New Jersey. 